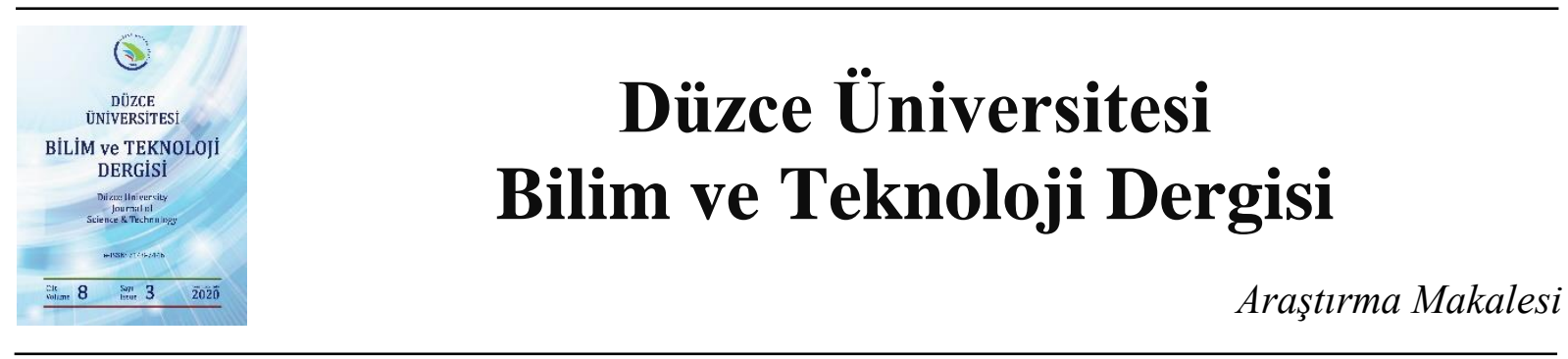

\section{Bilişsel Radyo Uygulamaları için Uzun Süreli Spektrum Doluluk Ölçümleri: Samsun Şehir Merkezi Örneği}

\author{
Zafer Emre ALBAYRAK a, (D) Çetin KURNAZ ${ }^{\text {a, *, (D) Serap KARAGÖL }}{ }^{\text {a }}$ \\ ${ }^{a}$ Elektrik-Elektronik Mühendisliği Bölümü, Mühendislik Fakültesi, Ondokuz Mayıs Üniversitesi, Samsun, \\ TÜRKIYE \\ * Sorumlu yazarin e-posta adresi: ckurnaz@omu.edu.tr
}

DOI : 10.29130/dubited.671789

\begin{abstract}
ÖZET
$\mathrm{Bu}$ çalışmada Samsun şehir merkezinde $470 \mathrm{MHz}-790 \mathrm{MHz}$ frekans aralığında, spektrumun en yoğun olduğu bölgede, 7 farklı günde ve 14 farklı zamanda spektrum doluluk ölçümleri yapılmıştır. Ölçümlerde RTL2832UR820T spektrum analizörü kullanılmıştır. Spektrum doluluk değerlendirmelerinde referans olarak $-40 \mathrm{~dB}$ ve -45 $\mathrm{dB}$ sinyal gücü seçilmiştir. Ölçüm sonuçlarından spektrum doluluk oranlarının zamana bağlı olarak değişkenlik gösterdiği bazı kanalların gün içerisinde kullanılmadığı veya sinyal kalitesinin kullanılmayacak kadar düştüğü görülmüştür. $-40 \mathrm{~dB}$ referans sinyal seviyesi için $320 \mathrm{MHz}$ 'lik spektrumun en fazla \% 60'ı kullanılırken, $-45 \mathrm{~dB}$ için bu oran \%55'dir. Dolayısıyla seçilen ölçüm noktası için gün içinde $144 \mathrm{MHz}$ 'e yakın bir spektrum kullanılmamaktadır. $\mathrm{Bu}$ değer analog TV frekans bandında (470 $\mathrm{MHz}$ - $790 \mathrm{MHz}$ ) bilişsel radyo uygulamalarından olan IEEE 802.11 af ve IEEE 802.22 kablosuz sistemlerinin rahatlıkla kullanılabilir olduğunu göstermektedir.
\end{abstract}

Anahtar Kelimeler: Spektrum doluluk ölçümleri, TV beyaz boşluk, Bilişsel radyo

\section{Long Term Spectrum Occupancy Measurements for Cognitive Radio Applications: Samsun City Center Example}

\begin{abstract}
In this study, spectrum occupancy measurements were performed in seven different days and 14 different times between $470 \mathrm{MHz}$ and $790 \mathrm{MHz}$ frequency band in the most dense spectrum part of Samsun city center. RTL2832U-R820T spectrum analyzer was used for measurements. In the spectrum occupancy evaluations, -40 $\mathrm{dB}$ and $-45 \mathrm{~dB}$ signal strength levels was selected as reference. It was seen from the measurement results that some channels where spectrum occupancy rates vary according to time are not used during the day or signal quality is reduced to not use. Up to $60 \%$ of the $320 \mathrm{MHz}$ spectrum is used for the $-40 \mathrm{~dB}$ reference signal level, while for $-45 \mathrm{~dB}$ this rate is $55 \%$. Therefore, a spectrum close to $144 \mathrm{MHz}$ per day is not used for the selected measurement location. This value shows that the cognitive radio applications such as IEEE 802.11af and IEEE 802.22 wireless systems in analog TV frequency band (470 MHz-790 MHz) can be used easily.
\end{abstract}

Keywords: Spectrum occupancy measurement, TV white space, Cognitive radio

Geliş: 07/01/2020, Düzeltme:07/04/2020, Kabul: 15/05/2020 


\section{GIRIS}

Kablosuz haberleşme sistemlerine olan talebin artması, kullanıcıların yüksek veri hızı gerektiren servisleri her geçen gün daha fazla kullanmaları, frekans spektrumunu daha etkin ve verimli kullanılması gerektiği gerçeğini gün yüzüne çıkarmıştır [1]. Kablosuz servisler, kullanıcı taleplerini karşılamak üzere sınırlı bir kaynak olan frekans spektrumunda en uygun çözümü aramaktadırlar. Diğer taraftan birçok lisanslı spektrum bandı (belirli bir servis için veya bir operatöre ayrılmış bant) ya kullanılmamakta ya da kullanım zamanı değişkenlik göstermektedir. Frekans spektrumu kullanım ölçümlerinde spektrumun zamanda ve uzayda düşük yoğunlukta kullanıldığının gözlenmesi spektrum boşluğu kavramının doğmasına neden olmuştur [2-4]. Lisanslı bir servise/operatöre tahsis edilmiş ancak belirli bir zaman ve coğrafyada lisans sahibi tarafından kullanılmayan frekans bandı spektrum boşluğu olarak ifade edilir. Kullanım oranlarının düşük seviyelerde olduğu frekans bantlarının dinamik olarak diğer kullanıcıların erişimine açılarak bilişsel radyo (cognitive radio) adı verilen kablosuz haberleşme sistemleri tarafından kullanılması, spektrum yetersizliği sorunu için bir çözüm önerisi olmuştur. Mitola tarafından 1999 yılında ilk olarak gündeme getirilen Bilişsel Radyo (BR) kavramı [5], frekans spektrumunu algılayarak kullanılmayan frekans bantlarını belirleyen ve sistemin çalışma parametrelerini bu boş bantta yayın yapabilecek şekilde uyarlayabilen bir radyo sistemidir. Bilişsel radyo sisteminde, frekans tahsisi yapılan ve kullanım önceliği olan lisanslı kullanıcılar birincil kullanıcı (primary user), frekans spektrumu algılayıp birincil kullanıcılara herhangi bir girişime neden olmayacak şekilde aynı bantta yayın yapan kullanıcılara da ikincil kullanıcı (secondary user) adı verilir. İkincil kullanıcılar, spektrumu tarayarak en uygun iletim kanalını herhangi bir girişime neden olamayacak şekilde belirleyip, veri iletiminde kullanılacak olan modülasyon türü ve verici gücü gibi pek çok radyo parametresini kanal şartlarına göre gerçek zamanlı olarak ayarlar. Bilişsel radyo uygulamaları günümüzün güncel çalışma konularından olup literetürde bu konuda yapılan pek çok çalışma bulunmaktadır [6-13].

TV verici istasyonları geçmiş yıllarda geniş bir frekans spektrumuna statik olarak yerleştirildiklerinden günümüzde ayrılan bu bantların kullanım verimlilikleri oldukça düşüktür. Bilişsel radyo uygulamaları için hali hazırda bulunan verimsiz veya kullanılmayan TV bantlarını belirlemek üzerine yapılmış pek çok çalışma bulunmaktadır [14-25]. Kullanılmayan TV frekans bantları üzerinden yapılan haberleşmeye TV beyaz boşluk haberleşmesi (TV white space communications) adi verilmektedir [26, 27]. IEEE 802.11af (White-Fi ve Super Wi-Fi) ve IEEE 802.22 WRAN (Wireless Regional Area Network) kablosuz sistemleri bilişsel radyonun boş TV bandını (54 MHz ile $862 \mathrm{MHz}$ arası) kullandığı uygulamalarındandır [28-32]. TV frekans bantlarının doluluk oranlarının belirlenmesi ve bilişsel radyo uygulamaları için uygun olup olmadıklarının belirlenmesi günümüzün güncel çalışma konularındandır. Bu nedenle bu çalışmada Samsun şehir merkezinde spektrumun en yoğun olduğu bölgesinde [22, 23] $470 \mathrm{MHz}-790 \mathrm{MHz}$ frekans aralı̆̆ında spektrum doluluk ölçümleri yapılmıştır. Literatürdeki çalışmalardan farklı olarak TV frekans bandının zamansal doluluk ölçümleri 7 ardışık günde ve günün iki farklı zaman dilimde (sabah ve akşam saatlerinde) yapılmış ve spektrumun hangi verimlikte kullanıldığ incelenmiştir.

Makalenin geri kalanı şu şekilde organize edilmiştir: II. Bölümde Dinamik Spektrum Erişimi ve Bilişsel Radyo sistemleri hakkında bilgiler sunulurken, III. Bölümde zamansal spektrum ölçümlerin alınmasına yönelik materyal ve yöntem bilgileri verilmiştir. IV. Bölümde ise analog TV frekans bandında (470 MHz - $790 \mathrm{MHz})$ yapılan spektrum doluluk ölçümlerinin sonuçları verilerek değerlendirmeler yapılmıştır. Makale V. Bölüm olan Sonuçlar bölümü ile sonlandırılmıştır.

\section{DINAMIK SPEKTRUM ERISSIMI VE BILLISSSEL RADYO}

Yüksek veri hızı gerektiren kablosuz servislere olan talebin her geçen gün artması, bu talebi karşılamak için kurulan servislerin çoğunlukla ISM (Industrial Scientific Medical) bantlarını kullanması spektrumunda bir sıkışıklık yaşanmasına neden olmuştur. Spektrum ölçümlerinden spektrum tahsisi yapılan servislerin büyük bir bölümünün spektrumu etkin bir şekilde kullanmadıkları 
görülmüştür. Özellikle lisanslı kullanıcılara ayrılan TV frekans bantlarının $(470 \mathrm{MHz}-790 \mathrm{MHz})$ çoğunluğunun boş olduğu pek çok çalışma ile doğrulanmıştır. Dolayısıyla hâlihazırda birincil kullanıcılara tahsis edilen spektrum etkin bir şekilde kullanılmaktadır. Yeni nesil kablosuz uygulamalar için frekans spektrumu tahsis edilememesinin altında yatan temel neden spektrum kıtlığ değil spektrumun verimli kullanılamamasıdır.

Frekans spektrumunun daha verimli kullanmak adına önerilen yöntemlerden bir tanesi dinamik spektrum erişimidir (DSE). DSE bulunduğu ortamda sürekli frekans spektrumunu tarayıp boş ya da daha az yoğun kullanımın olduğu kanalları arayarak, önceliğin her zaman birincil kullanıcıda olduğu bilinci ile spektrumun ikincil kullanıcılar ile paylaşılması temeline dayanmaktadır. DSE'nin zaman frekans düzlemi gösterilimi Şekil 1'de verilmiştir. Şekilden de görüldüğü gibi lisanslı kullanıcılar kendilerine ait spektrumu zamanın her anında kullanmamaktadırlar. $\mathrm{Bu}$ ise spektrum boşluklarının oluşmasına neden olmaktadır. Ayrıca kullanılan frekans değerine bağlı olarak lisanslı kullanıcıların güç değerleri de farklı olabilmektedir.

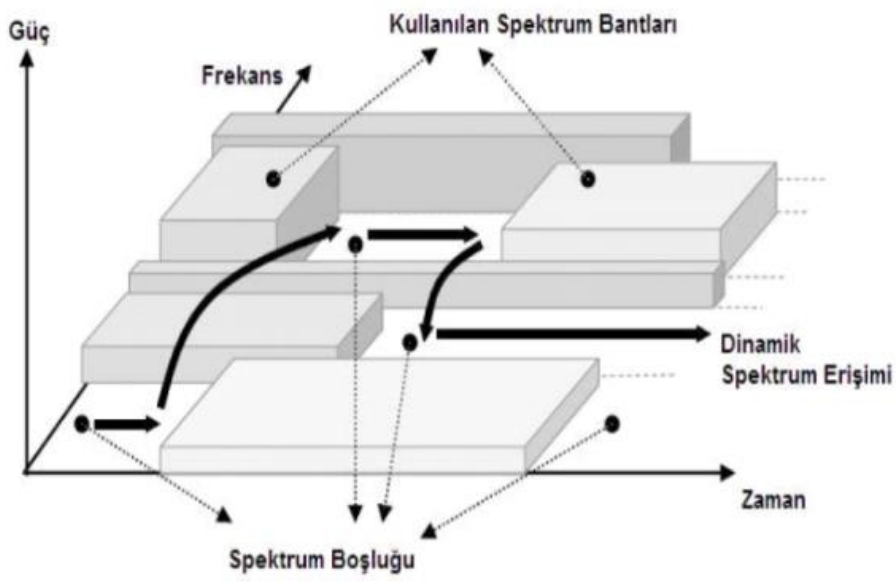

Şekil 1. Dinamik spektrum erişimi

Bilişsel radyo DSE'yi gerçekleyen bir yöntemdir. Bilişsel radyo yazılım tanımlı yapısıyla, bulunduğu ortam koşullarını algılayıp anlayarak, yayınım özelliklerini değiştirebilen akıllı bir kablosuz haberleşme sistemleridir [5]. BR uygulaması, ikincil kullanıcıların, birincil kullanıcılara herhangi bir bozucu etki yapmadan frekans spektrumunun ortaklaşa kullanılması temeline dayanır. BR çalışma prensipleri Şekil 2'de verilmiştir. Şekilden de görüldüğü gibi mavi renkle işaretlenen lisanslı kullanıcılara hizmet verilen bölgelerin dışında kalan yeşil bölgelerde bilişsel radyo uygulamaları yapılabilir. Bilişsel radyo sistemi, lisanslı (birincil) kullanıcıların yayın kalitesinde herhangi bir düşüş olmayacak şekilde ve sistemsel yapılarında herhangi bir değişikliğe gitmeden spektrumu ortaklaşa kullanabilir. 


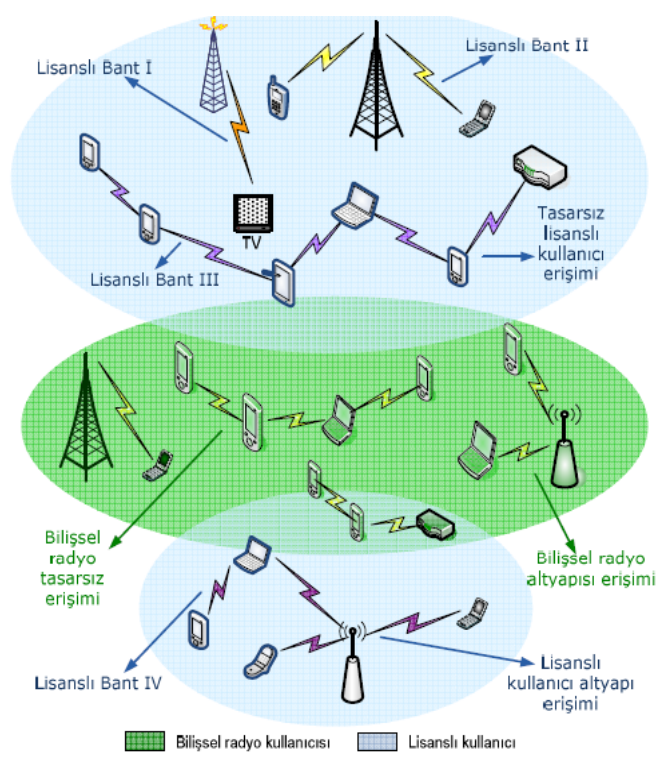

Şekil 2. Bilişsel radyo çalı̧̧ma prensibi

BR sisteminde birincil kullanıcı (lisanslı kullanıcı) frekans spektrumunu kullanmak için bir ücret ödemiş olup spektrum kullanım önceliğe sahip olan radyo cihazıdır. İkincil kullanıcı ise (lisanssız kullanıcı) bir frekans spektrumunu ancak boş ise kullanabilecek olan, birincil kullanıcılara göre daha az öncelikli kullanıcıdır. Birincil kullanıcılar, ikincil kullanıcılardan haberdar değillerdir. İkincil kullanıcılar spektrumu tarayarak (algılayarak) birincil kullanıcı tarafından kullanılmayan frekans spektrumunu fark edip o spektrumda yayın yaparlar. İkincil kullanıcı birincil kullanıcıya ait bir frekans bandını kullanırken eğer birincil kullanıcı yayına başlarsa en kısa sürede o spektrumu terk etmelidir. Ancak birincil kullanıcının fark edilmesi ve en kısa bir süre içinde birincil kullanıcıya spektrumun bırakılması oldukça zordur. BR sisteminin birincil kullanıcıya herhangi bir girişim yaratmaması için ikincil kullanıcı spektrumu en kısa sürede boşaltılmalıdır. IEEE 802.22 standartlarına göre kanal bırakma süresi 2 saniyeden az olmalıdır.

BR, bulunduğu farklı ortamlarla etkileşim halinde olan ve o anki ihtiyaçlarına göre iletim parametrelerini etkileşimsel olarak değiştirebilme ve adapte olabilme kabiliyetine sahiptir. Etkileşimsel yeteneği bilişsel döngü içinde Şekil 3'de verildiği gibi sezme, analiz ve karar verme gibi üç temel adımla ifade edilebilir. Sezme (spektrum algılama), kullanılmayan frekans spektrumu belirlemeyi ve birincil kullanıcılara herhangi bir girişime neden olmadan spektrumu paylaşmayı sağlar. Analiz (spektrum yönetimi) kullanıcı haberleşme parametrelerini belirlemek için en uygun kanalı bulmayı sağlar. Karar verme BR kullanıcıları arasında eşit olarak spektrumun paylaşılmasını sağlar.

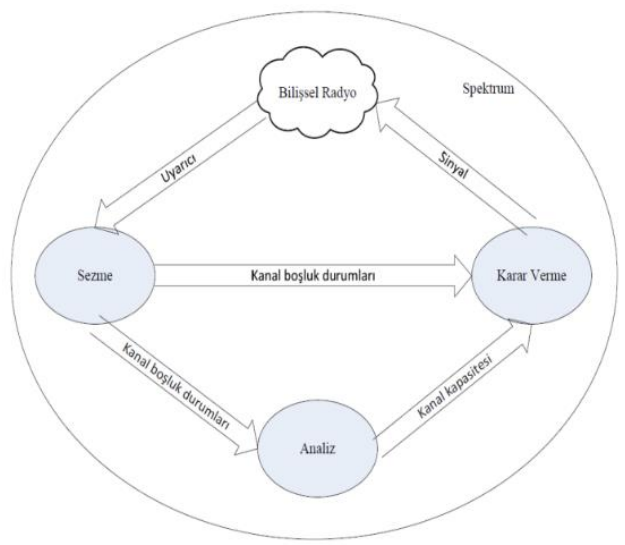

Şekil 3. Bilişsel radyo yapısı 


\section{ZAMANSAL ÖLCÜMLER}

Televizyon yayınında UHF (ultra high frequency) bandında kullanılmayan frekans bölümlerine televizyon beyaz boşlukları (TV white space) adı verilmektedir. Her bir ülkeye ait TV spektrumlarının ölçülmesi ve TV beyaz boşluklarının belirlenmesi günümüzün popüler çalışma alanlarındandır [1425]. Gelişmiş pek çok ülkede karasal/analog TV yayıncılığından sayısala TV yayıncılığına geçiş ile birlikte bu bantta boşalan veya kullanılmayan bantlar BR test çalışmaları için kullanmaya başlanmıştır. Türkiye'de karasal TV yayınları $470 \mathrm{MHz}$ ile $790 \mathrm{MHz}$ arasına konumlanmış olup bu aralıktaki kanalların her biri $8 \mathrm{MHz}$ yer kaplamakta ve toplamda bu frekans aralığında en fazla 40 TV kanalı yer almaktadır. Bu çalışmada Samsun Atakum ilçesinde $470 \mathrm{MHz}$ - $790 \mathrm{MHz}$ frekans aralığında spektrumun en yoğun olduğu bölgede [22, 23] farklı zamanlarda spektrum ölçümleri alınarak spektrum doluluk oranları ve TV kanallarının zamansal olarak değişimleri incelenmiştir. Kanalların zamansal değişimlerini analiz edebilmek amaciyla 7 farklı günde sabah ve akşam olmak üzere toplam 14 farklı zamanda ölçümler alınmıştır. Ölçümler Samsun ilinin UHF spektrumunun en yoğun olduğu bölgesi [22, 23] olan Atakum ilçesi Alaçam Caddesi üzerinde yapılmıştır. Ölçüm yapılan yerin konumu Şekil 4'de verilmiştir. Şekilde ölçüm konumu daire ile TV verici istasyonları ise (Tr1 ve Tr2) yıldız ile işaretlenmiştir. Ölçüm konumu her iki TV vericisini doğrudan gören bir noktada yer almaktadır.

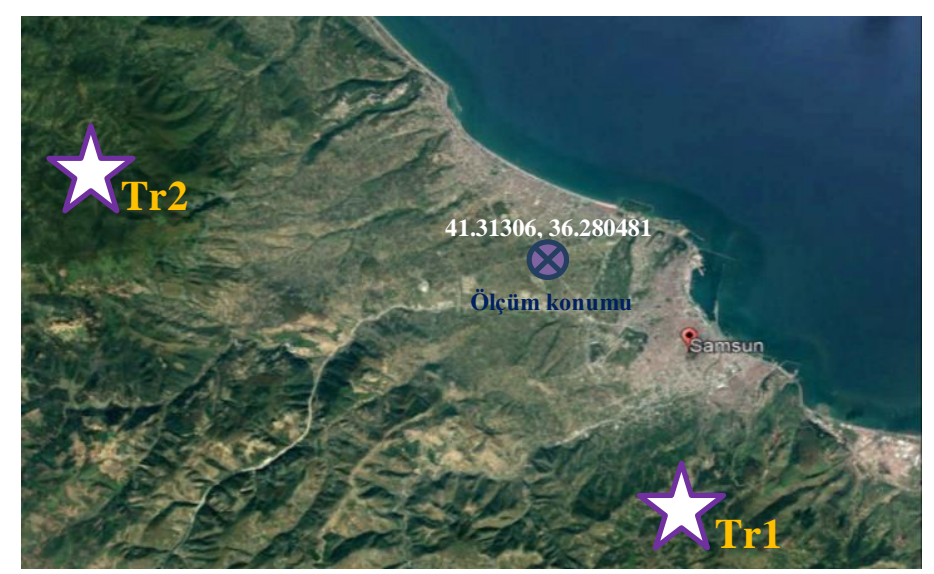

Şekil 4. TV spektrum ölçümlerinin yapıldlğg konum

Ölçümler RTL2832U R820T spektrum analizörü ile yapılmıştır. RTL2832U R820T belirlenen frekans aralıklarındaki sinyalleri tespit eden yazılım tabanlı radyo modeli ile çalışan bir cihazdır. Cihazın kendine özgü bir yazılımı bulunmakta olup diz üstü bilgisayara bu yazılım yüklenip anten kurulumu sonrasında ölçüm yapmaya hazır hale gelmektedir. $470 \mathrm{MHz}-790 \mathrm{MHz}$ arasındaki bir spektrum ölçümü ortalama 8 dakika sürmektedir. Ölçümlere ait görseller Şekil 5'de verilmiştir.

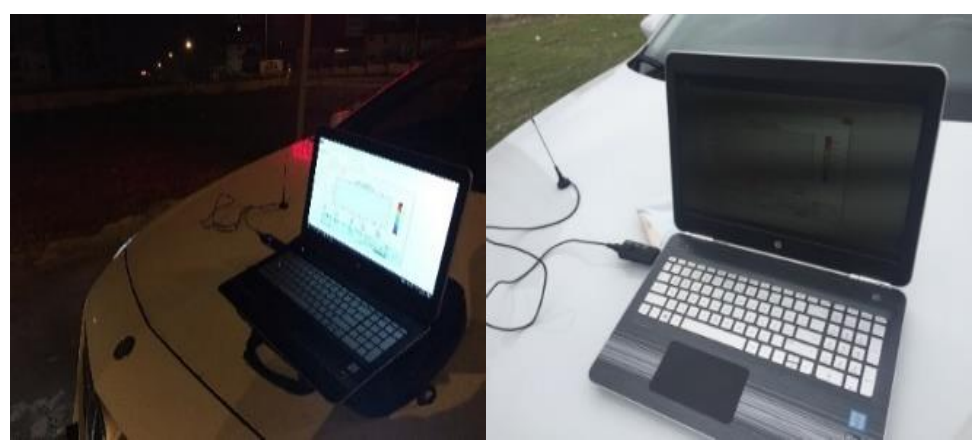

Şekil 5. Ölçümlere ait fotoğraflar 
RTL2832U R820T spektrum analizörü kullanılarak bir konumda alınan spektrum Şekil 6'da verilmiştir. Çalışmada $470 \mathrm{MHz}-790 \mathrm{MHz}$ arası spektrumu tam olarak değerlendirmek adına spektrum ölçümleri $450 \mathrm{MHz}$ ile $800 \mathrm{MHz}$ frekans aralığında yapılmış ve genlik değerleri kaydedilmiştir.

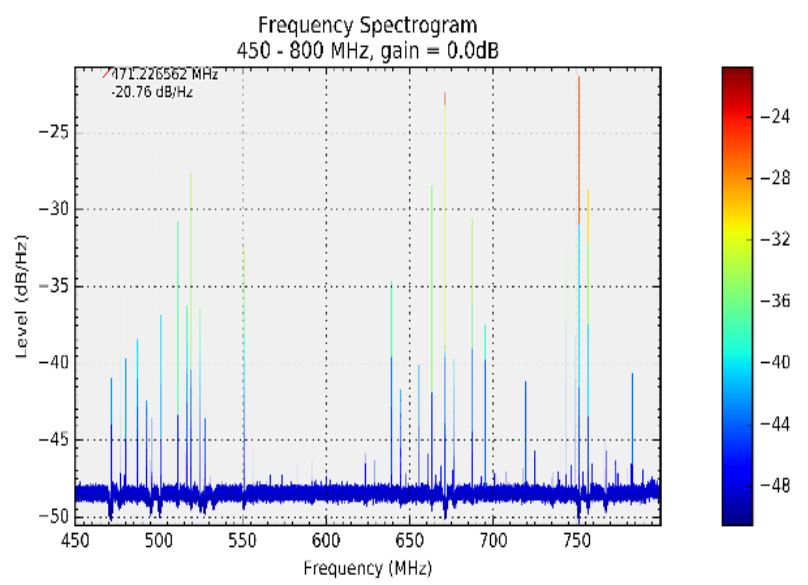

Şekil 6. RTL2832U R820T spektrum analizör ölçüm örneği

RTL2832U R820T Spektrum Analizörü ile 7 farklı günde sabah ve akşam saatlerinde alınan ölçümlerden elde edilen veriler MATLAB programı kullanılarak $470 \mathrm{MHz}-790 \mathrm{MHz}$ aralığında bulunan kanalların sayısı hesaplanmıştır. Kanal sayıları hesaplanırken $-40 \mathrm{~dB}$ ve $-45 \mathrm{~dB}$ genlik değerleri referans alınmış ve değerlendirmeleri görüntü sinyal taşıyıcısı genliğine göre yapılmıştır. Elde edilen kanal sayıları ile gün içindeki kanal sayısının zamansal değişimleri elde edilmiştir. MATLAB programı üzerinden kanal sayısının tespit edilmesi için tasarlanan örnek grafik Şekil 7 'de gösterilmiştir. Şekilde görüldüğü gibi sinyal gücü yaklaşık $-21 \mathrm{~dB}$ ile $-51 \mathrm{~dB}$ arasında değişmektedir. Gürültü tabanını ise $-48 \mathrm{~dB}$ civarındadır.

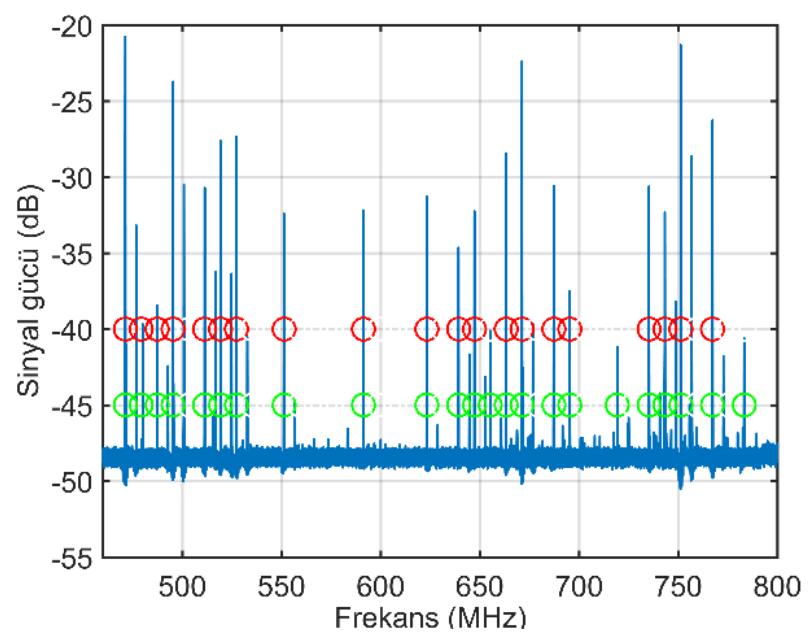

Şekil 7. MATLAB programı ile elde edilen örnek ölçüm grafiği

\section{IV. ÖLCÜM SONUCLARI}

Samsun ili, Atakum ilçesinde sabit bir konumda $470 \mathrm{MHz}-790 \mathrm{MHz}$ aralığında 7 farklı günün sabah ve akşam saatlerinde yapılan spektrum ölçüm sonuçları Şekil 8' de gösterilmiştir. Şekilden de görüldüğü gibi aynı konumda ölçülen sinyalin seviyesi zamana bağlı olarak anlamlı ölçüde değişkenlik göstermektedir. 


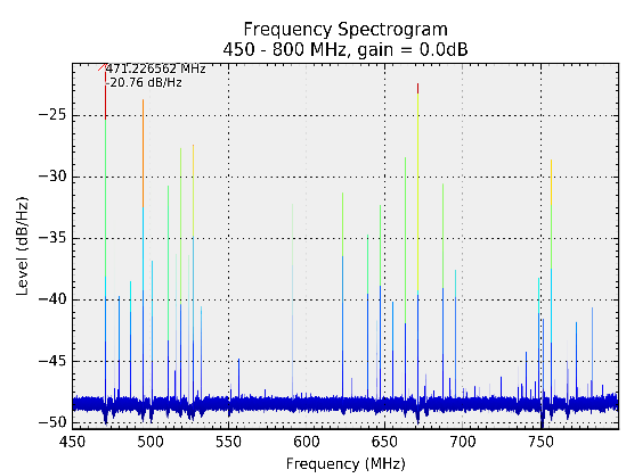

(a)

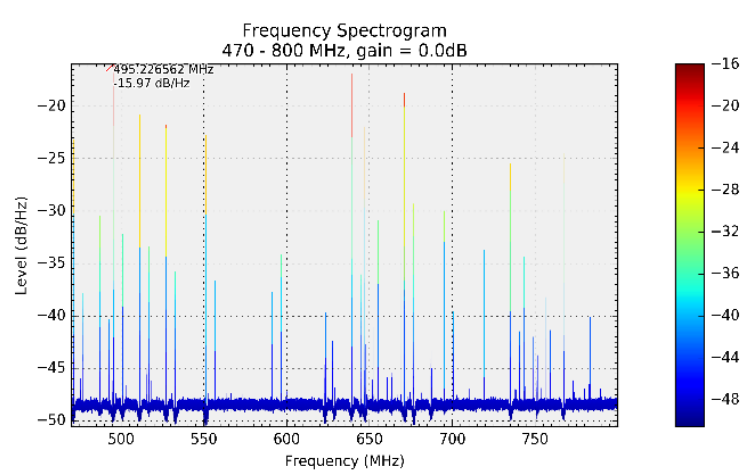

(c)

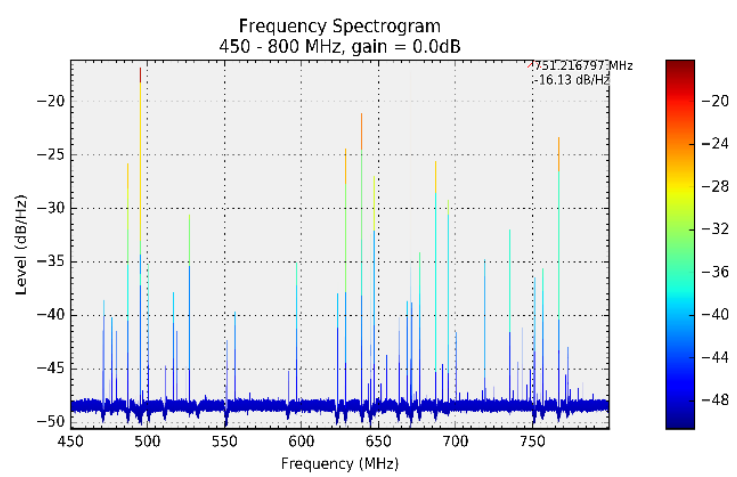

(e)

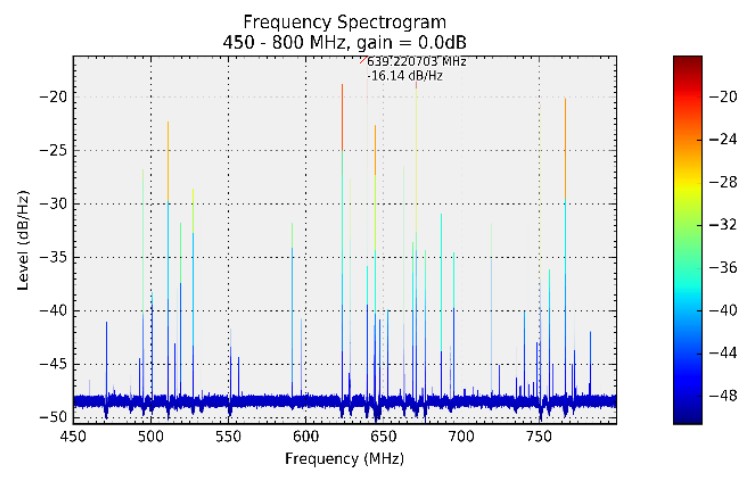

(g)

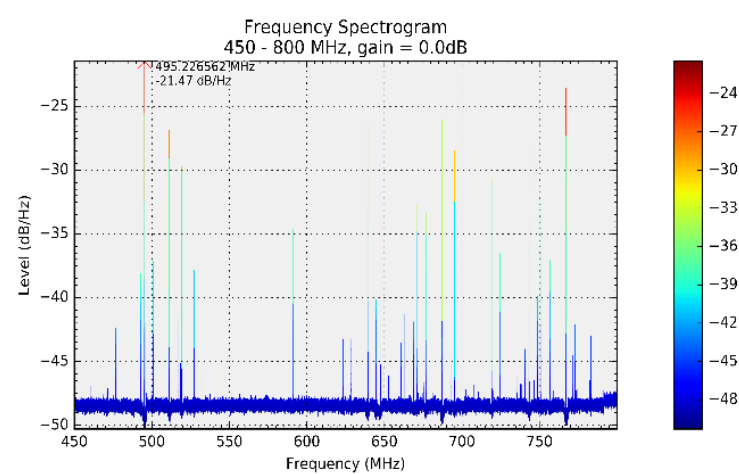

(b)

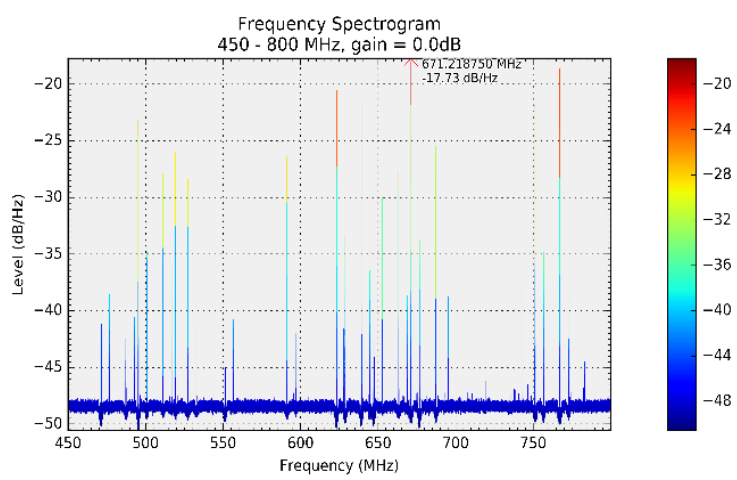

(d)

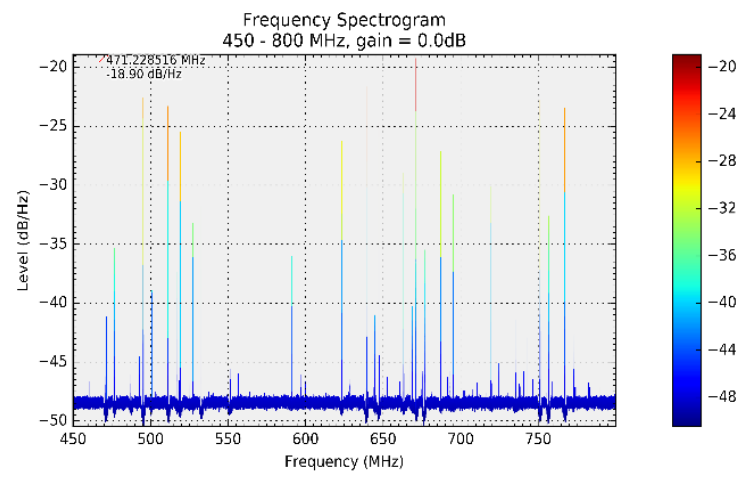

(f)

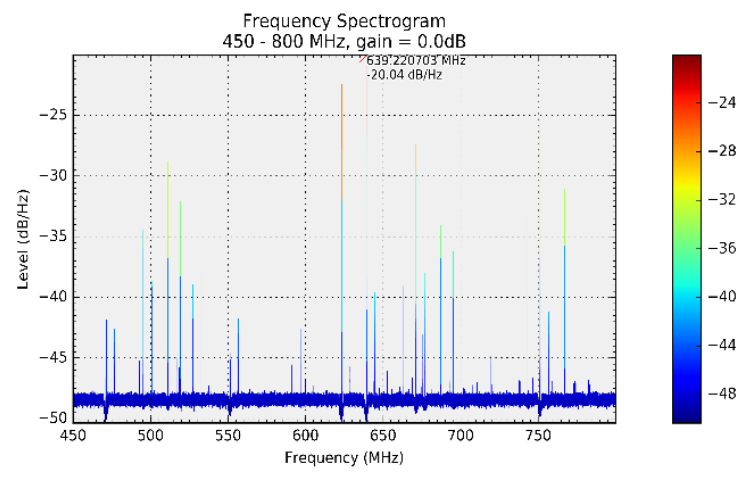

(h)

Şekil 8. (a) 1. Gün sabah, (b) 1. Gün akşam, (c) 2. Gün sabah, (d) 2. Gün akşam, (e) 3. Gün sabah, (f) 3. Gün akşam, (g) 4. Gün sabah, (h) 4. Gün akşam, (i) 5. Gün sabah, (j) 5. Gün akşam, (k) 6. Gün sabah, (l) 6. Gün akşam, (m) 7. Gün sabah, (n) 7. Gün akşam için ölçüm grafikleri 


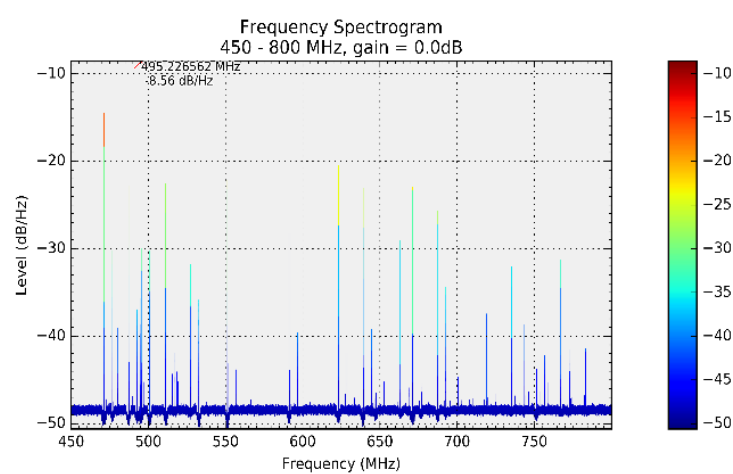

$(k)$

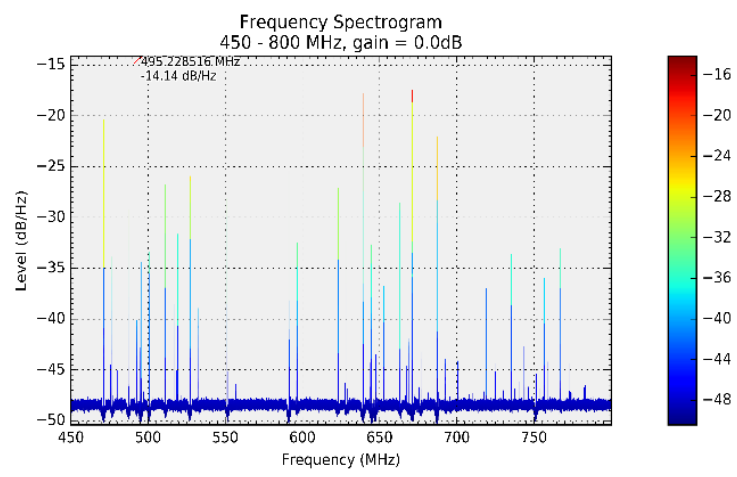

(m)

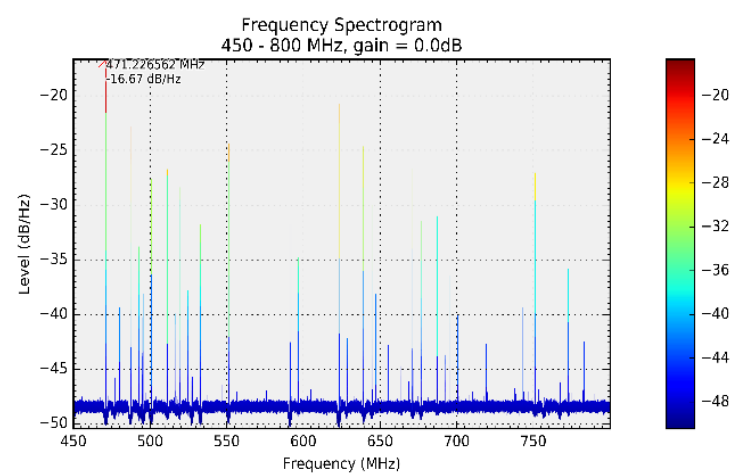

(l)

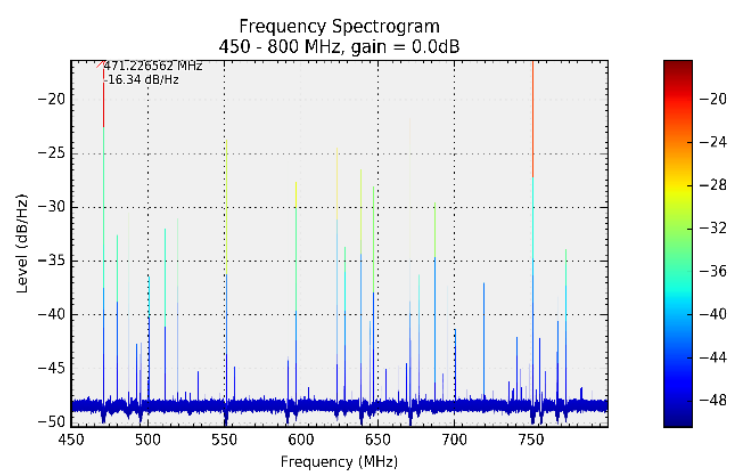

(n)

Şekil 8 (devam). (a) 1. Gün sabah, (b) 1. Gün akşam, (c) 2. Gün sabah, (d) 2. Gün akşam, (e) 3. Gün sabah, (f) 3. Gün akşam, (g) 4. Gün sabah, (h) 4. Gün akşam, (i) 5. Gün sabah, (j) 5. Gün akşam, (k) 6. Gün sabah, (l) 6. Gün akşam, (m) 7. Gün sabah, (n) 7. Gün akşam için ölçüm grafikleri

Ardışı 7 gün boyunca ve günün sabah ile akșam saatlerinde yapılan spektrum doluluk ölçümlerine ait her bir ölçüm verisi MATLAB programı dili kullanılarak Şekil 7'de verildiği gibi analiz edilmiştir. Analizlerde ilgilenen spektrumda TV kanalının var olup olmadığına $-40 \mathrm{~dB}$ ve $-45 \mathrm{~dB}$ referans sinyal seviyeleri kullanılarak karar verilmiştir. Analizler sonucunda $470 \mathrm{MHz}-790 \mathrm{MHz}$ frekans spektrumda yerleşen kanalların sayıs1 $-40 \mathrm{~dB}$ ve $-45 \mathrm{~dB}$ referans değerleri için Tablo 1'de verilmiştir. Tablo 1'de her bir spektrum ölçümü "Ö" kısaltması ile ifade edilmiş olup 7 gün süresince sabah ve akşam yapılan ölçümler Ö1 ile Ö14 arasında gösterilmiştir. Ö1, 1. gün sabah spektrum ölçümünü ifade ederken Ö14 ise 7. gün akşam ölçümünü temsil etmektedir. $8 \mathrm{MHz}$ bant genişlikli toplam 40 tane TV kanalının yerleşebileceği spektrumda, ölçüm konumu için spektrumda yerleşen en fazla kanal sayısı 24'dür. Bu değer 2. ölçüm gününün sabah saatinde (Ö3) ve $-45 \mathrm{~dB}$ referans sinyal seviyesi için hesaplanmıştır. Spektrumda yerleşen en az kanal sayısı ise 18 olarak $-40 \mathrm{~dB}$ referans seviyesi için Ö5 ve Ö8'de hesaplanmıştır.

Tablo 1. $470 \mathrm{MHz}-790 \mathrm{MHz}$ arası toplam kanal sayılart

\begin{tabular}{ccccc}
\hline \multirow{2}{*}{ Spektrum ölçümleri } & $\begin{array}{c}\mathbf{- 4 0 ~ d B} \text { referans sinyal } \\
\text { seviyesi için kullanılan } \\
\text { kanal sayısı }\end{array}$ & $\begin{array}{c}\text {-45 dB referans } \\
\text { sinyal seviyesi için } \\
\text { kullanılan kanal } \\
\text { sayısı }\end{array}$ \\
\hline \multirow{2}{*}{ Ö1 } & \multirow{2}{*}{ 1. Gün } & Sabah & 20 & 23 \\
\cline { 3 - 5 } Ö2 & \multirow{2}{*}{ 2. Gün } & Akşam & 19 & 23 \\
\cline { 3 - 5 } Ö3 & Sabah & 22 & 24 \\
\cline { 3 - 5 } Ö4 & \multirow{2}{*}{ 3. Gün } & Akşam & 20 & 22 \\
\cline { 3 - 5 } Ö5 & Sabah & 18 & 22 \\
\hline Ö6 & 4. Gün & Sabsam & 20 & 23 \\
\hline Ö7 & & & 22 & \\
\hline
\end{tabular}


Tablo 1 (devam). $470 \mathrm{MHz}-790 \mathrm{MHz}$ arası toplam kanal sayllart

\begin{tabular}{|c|c|c|c|c|}
\hline Ö8 & & Akşam & 18 & 20 \\
\hline Ö9 & \multirow{2}{*}{ 5. Gün } & Sabah & 19 & 23 \\
\hline Ö10 & & Akşam & 19 & 20 \\
\hline Ö11 & \multirow{2}{*}{ 6. Gün } & Sabah & 20 & 22 \\
\hline Ö12 & & Akşam & 20 & 23 \\
\hline Ö13 & \multirow{2}{*}{ 7. Gün } & Sabah & 19 & 21 \\
\hline Ö14 & & Akşam & 20 & 20 \\
\hline
\end{tabular}

Tablo 1 incelendiğinde $470 \mathrm{MHz}-790 \mathrm{MHz}$ arası toplam kanal sayısının güne ve gün içindeki zaman dilimine bağlı olarak değişkenlik gösterdiği görülmektedir. Bu değişim Şekil 9'da daha detaylı bir şekilde açıklanmıştır. Şekil 9. a'da 31. kanal için sabit bir konumdaki (kanal başlangıcı $550 \mathrm{MHz}$, kanal bitişi $558 \mathrm{MHz}$, görüntü taşıyıcı frekans1 $551.25 \mathrm{MHz}$, ses taşıyıcı frekans1 $556.75 \mathrm{MHz}$ ) frekans yerleşimi verilmiştir. Sabah saatlerinde görüntü taşıyıcı frekansının gücü $-33 \mathrm{~dB}$ değerlerinde iken, akşam saatlerinde sinyal seviyesi -40 dB'nin altına düşebilmektedir (Şekil 9. b). Kanal doluluk değerlendirmesi yapılırken $-40 \mathrm{~dB}$ referansı için Şekil 9.a için kanal sinyal seviyesi $-40 \mathrm{~dB}$ 'den daha büyük olduğundan dikkate alınırken Şekil 9. b için göz ardı edilmiştir.

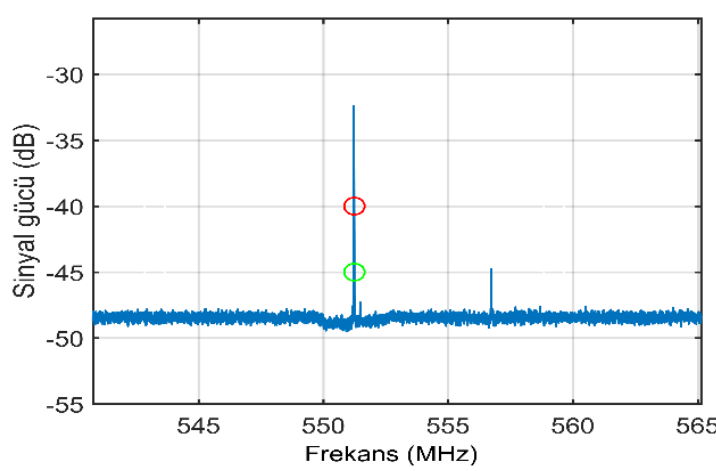

(a)

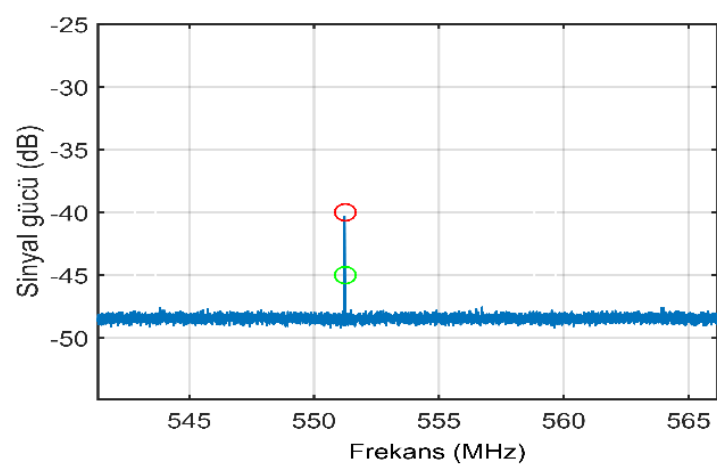

(b)

Şekil 9. 31. kanal için sinyal seviyesinin (a) sabah, (b) akşam için değişimi

Tüm ölçüm sonuçları dikkate alınarak doluluk oranları hesaplanmış, $-40 \mathrm{~dB}$ ve $-45 \mathrm{~dB}$ için sonuçlar Şekil 10'da verilmiştir. Şekil 10 incelendiğinde $-40 \mathrm{~dB}$ için en yüksek doluluk oranı $\% 60$ iken en düşük doluluk oranı \%50'dir. Toplam $320 \mathrm{MHz}$ frekans bandı düşünüldüğünde doluluğun en yüksek olduğu durumda bile $128 \mathrm{MHz}$ frekans bandı kullanılmamaktadır. $-45 \mathrm{~dB}$ için ise bu değer 144 MHz'lere kadar çıkabilmektedir. 


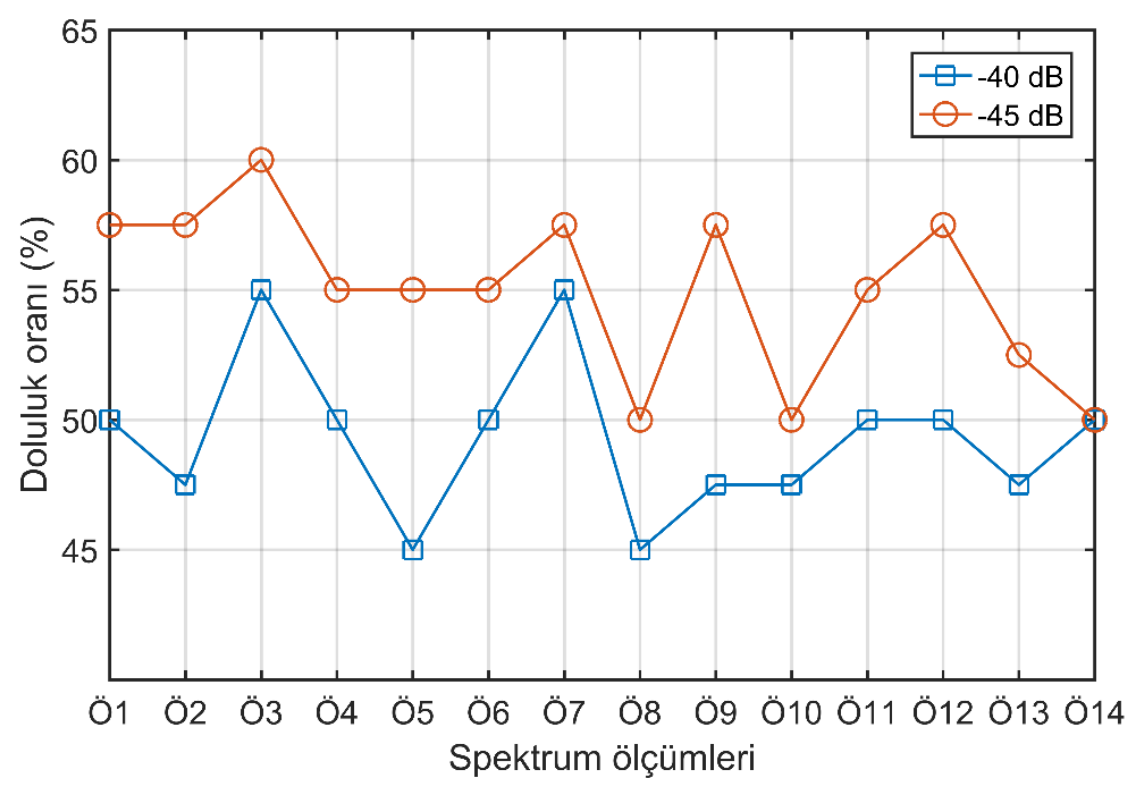

Şekil 10. -40 dB ve -45 dB için kanal doluluk oranlart

\section{SONUCLAR}

Bu çalışmada Samsun şehir merkezinde $470 \mathrm{MHz}$ ile $790 \mathrm{MHz}$ frekans aralığındaki spektrumun en yoğun olduğu bölgede [22, 23] yedi farklı günde spektrum ölçümleri (14 farklı ölçüm) yapılarak spektrumda yerleşen TV kanallarının gün içindeki genlik değişimleri incelenmiştir. Genlik değişimleri için $-40 \mathrm{~dB}$ ve $-45 \mathrm{~dB}$ sinyal seviyeleri referans alınarak değerlendirmeler yapılmıştır. Sonuçlarından TV spektrumunda yerleşen kanalların genlik değerlerinin zamanla değiştiği ve belirlenen referans seviyelerinin altına düştüğü görülmüştür. Spektrum ölçümleri analiz edildiğinde Samsun şehir merkezinde en yüksek doluluk oranı $\% 60$ olarak belirlenmiştir. Bu ise $470 \mathrm{MHz}-790 \mathrm{MHz}$ frekans aralığında $128 \mathrm{MHz}$ 'lik bir frekans bandın hiç kullanılmadığı anlamına gelmektedir. Ölçüm sonuçları bu değerin $176 \mathrm{MHz}$ 'e kadar da (\%45 doluluk durumu için) çıkabildiğini göstermiştir. Bu sonuçlar Samsun şehir merkezinde bilişsel radyo teknolojilerinden olan IEEE 802.11af (WLAN, toplam bant genişliği 5, 10, 20, $40 \mathrm{MHz}$ [32]) ve IEEE 802.22 (WRAN, toplam bant genişliği 6, 7, $8 \mathrm{MHz}$ [32] kablosuz sistemlerin rahatlıkla kullanılabilir olduğunu göstermektedir.

\section{KAYNAKLAR}

[1] FCC, In the matter of unlicensed operation in the TV broadcast bands, additional spectrum for unlicensed devices below $900 \mathrm{MHz}$ and in the $3 \mathrm{GHz}$ band, Report ET docket no. 08-260, 2008.

[2] S. Haykin, "Cognitive radio: brain-empowered wireless communications," IEEE Journal on Selected Areas in Communications, vol. 23, no. 2, pp. 201-220, 2005.

[3] I. F. Akyildiz, W. Lee, M. C. Vuran, S. Mohanty, "Next generation/dynamic spectrum access/cognitive radio wireless networks: a survey," Computer Network, vol. 50, no. 13, pp. 21272159, 2006.

[4] S. M. Mishra, "Maximizing available spectrum for cognitive radios" Ph.D dissertation, University of California, Berkeley, USA, 2010. 
[5] J. Mitola, G. Q. Maguire, "Cognitive radio: Making software radios more personal," IEEE Personal Communications, vol. 6, no. 4, pp. 3-18, 1999.

[6] W. Zhang, Y. Sun, L. Deng, C. K. Yeo and L. Yang, "Dynamic Spectrum Allocation for Heterogeneous Cognitive Radio Networks With Multiple Channels," IEEE Systems Journal, vol. 13, no. 1, pp. 53-64, 2019.

[7] Z. Gu, T. Shen, Y. Wang and F. C. M. Lau, "Efficient Rendezvous for Heterogeneous Interference in Cognitive Radio Networks," IEEE Transactions on Wireless Communications, vol. 19, no. 1, pp. 91-105, 2020.

[8] Z. Qin, X. Zhou, L. Zhang, Y. Gao, Y. Liang and G. Y. Li, "20 Years of Evolution From Cognitive to Intelligent Communications," IEEE Transactions on Cognitive Communications and Networking, vol. 6, no. 1, pp. 6-20, 2020.

[9] Y. Arjoune, N. Kaabouch, "A Comprehensive Survey on Spectrum Sensing in Cognitive Radio Networks: Recent Advances, New Challenges, and Future Research Directions," Sensors (Basel), vol. 19, no.126, pp. 1-32, 2019.

[10] M. E. Bayrakdar, A. Çalhan, "Kablosuz Bilişsel Radyo Ağlarında İkincil Kullanıcılar için Ortam Erişim Kontrol Protokolleri," Pamukkale Üniversitesi Mühendislik Bilimleri Dergisi, vol.23, no.2, pp.149-164, 2017.

[11] M. E. Bayrakdar, A. Çalhan, "Performance Analysis of Slotted Aloha Protocol in Wireless Cognitive Radio Networks," Balkan Journal of Electrical \& Computer Engineering, vol.3, no.4, pp.248-251, 2015.

[12] M. E. Bayrakdar, A. Çalhan, "Decision System for Rule based Spectrum Handoff Process of Secondary Users," Mugla Journal of Science and Technology, vol.3, no.1, pp. 27-30, 2017.

[13] M. E. Bayrakdar, A. Çalhan, "Kablosuz Bilişsel Radyo Ağlarında Spektrum El Değiştirme için Öncelik Kuyrukları ve Yapay Zeka Teknikleri," Niğde Ömer Halisdemir Üniversitesi Mühendislik Bilimleri Dergisi, vol.6, no.2, pp.303-315, 2017.

[14] D. C. Hieu, P. V. Tien, "Assessment of TV White Space in Vietnam," International Conference on Advanced Technologies for Communications, Vietnam, Oct. 15-17, 2014.

[15] N. Wang, T. Gao, Y. Chen, E. Bodanese, L. Cuthbert, "Performance Evaluation of Power Control Algorithm for TV White Space Resource in UK," presented at 7th International ICST Conference on Communications and Network in China, Kunming, China. 2012.

[16] T. Shimomura, T. Oyama, H. Seki, “Analysis of TV White Space in Japan," presented at IEEE Vehicular Technology Conference (VTC Fall), Quebec, Canada. 2012.

[17] J. V. Beek, J. Riihija, A. Achtzehn, M. Petri, "IEEE TV white space in Europe," IEEE Transaction on Mobile Computing, vol. 11, no. 2, pp. 178-188, 2012.

[18] M. Nekovee, "Cognitive radio access to TV white spaces: spectrum opportunities, commercial applications and remaining technology challenges," presented at IEEE Symposium on New Frontier in Dynamic Spectrum, Singapore, Singapore. 2010.

[19] R. Jantti, J. Kerttula, K. Koufos, K. Ruttik, "Aggregate interference with FCC and ECC white space usage rules: case study in Finland," presented at IEEE Symposium on New Frontier in Dynamic Spectrum Access Networks, Aachen, Germany. 2011. 
[20] P. Flynn, "White space potentials and realities," White paper, Texas instruments, Texas, USA, Jan. 2013. [Online]. Available: http://www.newelectronics.co.uk/article-images/47921/spry227.pdf

[21] G. Naik, S. Singbal, A. Kumar, A. Karandikar, "Quantitive assessment of TV white space in India," presented at 20th National Conference on Communications, Kanpur, India. 2014.

[22] Ç. Kurnaz, Z. E. Albayrak, "Measuring and evaluating TV white spaces in Samsun, Turkey," Journal of New Results in Science, vol. 12, pp. 139-148, 2016.

[23] Ç. Kurnaz, B. K. Engiz, Z. E. Albayrak, "Determination of TV white space spectrum availability in Samsun Turkey," presented at 24th Telecommunications Forum TELFOR, Belgrade, Serbia. 2016.

[24] H. Maloku, Z. L. Fazliu, M. Ibrani, A. Mekuli, E. Sela, M. Rajarajan, "Measurement of Frequency Occupancy Levels in TV Bands in Urban Environment in Kosovo," presented at 18th Mediterranean Microwave Symposium (MMS), Istanbul, Turkey, 2018.

[25] R. T. Loquias, C. A. G. Hilario, M. F. D. d. Guzman, J. J. S. Marciano, "Quantitative Assessment of TV White Space in the Western Philippine Nautical Highway," presented at IEEE International Symposium on Dynamic Spectrum Access Networks (DySPAN), Newark, NJ, USA, 2019.

[26] S. W. Oh, Y. Ma, M.H. Tao, E. Peh, "TV White Space: The First Step Towards Better Utilization of Frequency Spectrum," Wiley-Blackwell, 2016.

[27] A. K. Mishra, D. L. Johnson, "White Space Communication Advances, Developments and Engineering Challenges," Springer International Publishing, 2015.

[28] J. H. Martin, L.S. Dooley, K.C.P. Wong, "Cognitive Radio and TV White Space (TVWS) Applications. In: W. Zhang (eds) Handbook of Cognitive Radio”. Springer, 2019.

[29] Z. Zhao, M. C. Vuran, D. Batur, E. Ekici, "Shades of White: Impacts of Population Dynamics and TV Viewership on Available TV Spectrum," IEEE Transactions on Vehicular Technology, vol. 68, no. 3, pp. 2427-2442, 2019.

[30] L. S. Aji, F. H. Juwono, G. Wibisono, D. Gunawan, "Proposal for Improving White-Space Channel Availability," IEEE Access, vol. 6, pp. 59528-59539, 2018.

[31] W. Zhang, J. Yang, G. Zhang, L. Yang, C. Kiat Yeo, "TV white space and its applications in future wireless networks and communications: a survey," IET Communications, vol. 12, no. 20, pp. 2521-2532, 2018.

[32] D. Lekomtcev, , R. Maršálek, "Comparison of 802.11 af and 802.22 standards - physical layer and cognitive functionality," Elektrorevue, vol.3, no.2, pp.12-18, 2012. 